\title{
VAŽNOST NALAZA FUNDUSA U PROCJENI ARTERIJSKE HIPERTENZIJE
}

\section{Sažetak}

$U$ radu se iznose rezultati nalaza na fundusu kod 226 hipertoničara u odnosu na visinu dijastoličkog tlaka i dob bolesnika, te promjene na fundusu u toku terapije.

Nalaz na fundusu je jedan od najvažnijih nalaza u procjeni težine arterijske hipertenzije. Sa porastom dijastoličkog tlaka raste težina promjena na fundusu. Uz visinu dijastoličkog tlaka, značajnu ulogu ima duljina trajanja hipertenzije i dob bolesnika.

Ključne riječi: arterijska hipertenzija, dijastolički tlak, hipertonični fundus.

\section{Uvod}

Hipertenzija danas zauzima značajno mjesto u morbiditetu i mortalitetu stanovništva. Oko $10 \%$ odraslog stanovništva boluje od hipertenzije. U kliničkoj obradi hipertoničara sve veći značaj se daje nalazu fundusa $\mathrm{u}$ procjeni težine oboljenja, kao i praćenju uspjeha terapije.

Da bismo ocijenili kakva je korelacija visine dijastoličkog tlaka i nalaza na fundusu u procjeni težine hipertenzije, izvršili smo pregled 226 hipertoničara ambulantno na Očnom odjelu Kantonalne bolnice Dr. Irfan Ljubijankić u toku 2011. i 2012. godine.

Promjene na fundusu su sistematizirane prema klasifikaciji po Keith, Wagneru i Barkeru iz 1939. godine. Kod Fundus hypertonicus III i IV stupnja vršili smo kontrolne preglede fundusa radi praćenja uspjeha terapije.

\footnotetext{
${ }^{1}$ Visoka zdravstvena škola u Bihaću.
} 


\section{PODJELA HIPERTONIČNOG FUNDUSA PREMA KEITH, WAGNERU I BARKERU (1939.)}

\section{FUNDUS HYPERTONICUS}

I stupanj-lahka suženja arteriola, početni znaci križanja,

II stupanj - znaci skleroze, difuzna ili segmentalna suženja arteriola, Gunn, Salus, Quist poz.

III stupanj - jača arterioskleroza, edem retine, cotton-woll eksudati, krvarenja,

IV stupanj - III stadij + edem papile i zvjezdasta figura. $K$

\section{PODJELA PO A. MARKOVIĆU}

I + II stupanj

III stupanj

IV stupanj
Fundus hypertonicus

Retinopathia hypertonica

Retinopathia hypertonica maligna

2.

\section{ILJ IS T R A Ž IV A NJA}

Cilj istraživanja je utvrditi korelaciju između visine dijastoličkog tlaka i promjena na fundusu oka s obzirom na visinu dijastoličkog tlaka, te vidjeti da li viši dijastolički tlak dovodi do težih promjena na fundusu i u kojem vremenskom periodu.

\section{BOLESNICIIMETODE ISTRAŽIVANJA}

Bolesnici su bili pacijenti koji su upućeni od strane interniste radi pregleda fundusa oka direktnom oftalmoskopijom. Svi pacijenti su praćeni kroz period od dvije godine,a uzimali su redovito antihipertenzivnu terapiju koju je odredio internista. Svaki pacijent je kontrolisan $4 \mathrm{x}$ godišnje u periodu od dvije godine. 


\section{R E Z U L T A T I}

Tabela 1

SPOL

$\begin{array}{lcccccc}\mathbf{M} & \mathbf{0}^{\circ} & \mathbf{I}^{\circ} & \mathbf{I I}^{\circ} & \mathbf{I I I}^{\circ} & \mathbf{I V}^{\circ} & \mathbf{U K U P N O}^{\circ} \\ \check{\mathbf{Z}} & 25 & 54 & 67 & 8 & 2 & \mathbf{1 5 6} \\ & 16 & 15 & 37 & 1 & 1 & \mathbf{7 0}\end{array}$

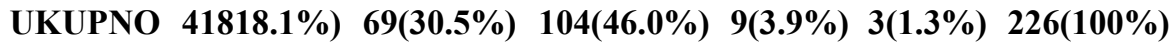

- Od 226 pregledanih, većinu čine muškarci - 156 ili 69,02 \% pacijenata, a žene 70 ili $31,9 \%$.

- Normalan nalaz na fundusu našli smo kod 41 osobe, ili $18,1 \%$.

- Fundus hypertonicus I stupnja našli smo kod 69 ili 30, 5\%, II stupnja kod 104 osobe ili 46,0 \%, III stupnja kod 9 ili 3,9\%,a IV kod 3 ili 1,3\% osoba.

3.

Tabela 2

\begin{tabular}{|c|c|c|c|c|c|c|}
\hline \multirow{2}{*}{ DOB } & \multicolumn{5}{|c|}{ FUNDUSI } & \multirow{2}{*}{ UKUPNO } \\
\hline & $0^{\circ}$ & $I^{\circ}$ & II $^{\circ}$ & IIII $^{\circ}-(-2)$ & $I^{\circ}$ & \\
\hline do 20 god. & 2 & 1 & -- & -- & -- & 3 \\
\hline 21 - 30 god. & 25 & 4 & 2 & -- & -- & 31 \\
\hline 31 - 40 god. & 13 & 35 & 11 & 2 & 1 & 62 \\
\hline $41-50 \operatorname{god}$ & 1 & 15 & 57 & 3 & -- & 76 \\
\hline 51 - 60 god. & -- & 15 & 26 & 1 & 2 & 44 \\
\hline preko 60 god. & -- & -- & 8 & 1 & 1 & 10 \\
\hline UKUPNO & 41 & 70 & 104 & 7 & 4 & 226 \\
\hline
\end{tabular}

- Hipertenzija je bila zastupljena u svim dobnim grupama, ali najviše hipertoničara je bilo u dobi od 40 - 50 godina $(33,6 \%)$.

- Do 30 godina starosti dominirao je normalan nalaz na fundusu, ili u $83 \%$, Fundus hypertonicus I stupnja u $12 \%$, a u II stupnja $5 \%$. 
- Iznad 30 godina postoje svi stupnjevi promjena na fundusu, iako većinu teških, hipertenzivnih promjena nalazimo u dobi iznad 40 godina starosti.

\section{Tabela 3}

Dijastolički tlak

Do 110mm Hg

111-130 mm Hg

Preko 130 mm Hg

$\begin{array}{cc}\mathbf{0}^{\circ} & \mathbf{I}^{\circ} \\ 15 & 14 \\ 25 & 53 \\ 1 & 3\end{array}$

\section{FUNDUSI}

II $^{\circ} \quad$ III $^{\circ}$

$5 \quad--$

$82 \quad 4$

$17 \quad 4$

$\mathbf{I V}^{\circ}$
--
1
2

3

\section{UKUPNO}

34

165

27

226

- Sa porastom dijastoličkog tlaka raste i učestalost težine promjene na fundusu.

- Tek iznad $110 \mathrm{~mm} \mathrm{Hg}$ dijastoličkog tlaka mogli su se naći svi stupnjevi hipertenzivnih promjena na fundusu.

- Kod 27 hipertoničara sa dijastoličkim tlakom iznad $130 \mathrm{~mm} \mathrm{Hg}$, 4 ih je bilo III, a 2 osobe IV stupnja - zajedno 11,9\%.

- Normalan nalaz na fundusu sa porastom tlaka je opadao.

- Tako je u grupi hipertoničara do $110 \mathrm{~mm} \mathrm{Hg}$ dijastoličkog tlaka, normalan nalaz bio u $44 \%$, od 111 - $130 \mathrm{~mm} \mathrm{Hg}$ kod 15,5 \%, a u grupi iznad $130 \mathrm{~mm} \mathrm{Hg}$ samo $4 \%$.

\section{DISKUSIJA}

Naši rezultati potvrđuju da postoji korelacija između visine dijastoličkog tlaka i težine promjena na fundusu. Dok u grupi hipertoničara sa dijastoličkim tlakom do $110 \mathrm{~mm} \mathrm{Hg}$ nismo imali hipertenzivnu retinopatiju, a normalan nalaz smo našli u $44 \%$, u grupi hipertoničara sa dijastoličkim tlakom iznad 130 mm Hg u $18 \%$ smo imali hipertenzivnu retinopatiju, a normalan nalaz samo kod $4 \%$ hipertoničara. Uzevši sve grupe u obzir, najzastupljeniji je bio Fundus hypertonicus II stupnja u 47 $\%$, zatim I stupnja sa $31,4 \%$, III stupnja sa $2 \%$ i IV sa $0,9 \%$. 
Normalan nalaz na fundusu našli smo kod $18,7 \%$ hipertoničara, dok je u grupi do 30 godina starosti normalan nalaz bio u $83 \%$.

Ovo potvrđuje da u težini hipertenzivnih promjena, pored visine tlaka, značajnu ulogu ima vrijeme nastanka i duljina trajanja hipertenzije.

U toku retrospektivne studije toka arterijske hipertenzije kod 242 hipertoničara, Šarić sa saradnicima nalazi, prema raspoloživim podacima za 132, normalan nalaz na fundusu u $38 \%$ na početku ispitivanja, a poslije $10-15$ godina trajanja hipertenzije - samo u 4,1\%. Dok je ukupan mortalitet grupe kroz navedeni period bio 14,6 \%, zbog hipertenzije je umrlo $8,9 \%$. Svardsud sa saradnicima 1978. godine iznosi rezultate desetogodišnje prospektivne studije hipertenzivnih promjena na fundusu kod 855, prema datumu rođenja odabranih, pedesetogodišnjaka. Oni su dokazali da su sve promjene na fundusu kao: suženja arteriola, fokalna suženja, fenomeni križanja, proširenje refleksa, hemoragije i eksudati - signifikantno učestalije kod hipertoničara nego kod normotenzivnih. Suženje arteriola je najsenzibilnije i najspecifičnije od svih znakova, kako u otkrivanju hipertoničara, tako i u isključivanju normotenzivnih.

Učestalost kardiovaskularnih komplikacija je signifikantno veća kod fokalnih suženja arteriola vidljivih na fundusu.

Kod $3 \%$ naših hipertoničara promjene na fundusu su bile III i IV stupnja. Oni su stalno bili pod našom kontrolom uz intenzivnu internističku antihipertenzivnu terapiju vazodilatatorima, beta blokatorima i diureticima, a kod 7 najtežih primijenjen je poseban tretman minoksidilom. Promjene na fundusu mijenjale su se u skladu sa poboljšanjem općeg kliničkog stanja. Od njih 7, 4 pacijenta su sada na kroničnoj dijalizi, dok je kod ostalih stanje zadovoljavajuće.

Nalaz na fundusu mekanih cotton-wool eksudata uz plamenaste heloragije su indikator akceleracije hipertenzije, prisustvo nekrotizirajućeg arteriolitisa uz teška renalna oštećenja.

Prema Leishmanu, strukturna oštećenja pripadajućih arteriola uzrokuju opisane probleme. Okluzija i nekroza arteriola su glavni uzrok, te se radi 
o blijedim infarktima. Do istih rezultata došao je i Asthon patohistološkim studijama, kao i eksperimentima na životinjama, izazivajući okluziju arteriola suspenzijama staklenih kuglica promjera 15 - 45 mikrona. Cotton-wool nisu specifični samo za hipertenziju, jer se javljaju i kod kolagenoza, dijabetesa, krvnih bolesti kao i kod svih oboljenja prema Leinfelderu gdje postoje mikro emboli.

Dok prema Leishmanu, Kleinu, Duke Elderu cotton-wool predstavljaju citoidna tijela (degenerirane aksone ganglijskih stanica) u edematoznoj areji i indikator su akceleracije hipertenzije, tvrdi eksudati koji leže dublje, a mogu formirati i zvjezdastu figuru, su znaci kroniciteta. Predstavljaju nakupine lipoida i hijalina. Meki eksudati nastaju poslije 6 - 8 sedmica, a tvrdi mogu ostati mjesecima pa i godinama. Ovo smo mogli potvrditi i kod naših hipertoničara.

\section{2.}

Retinalna krvarenja najčešće se pojavljuju blizu optičkog diska u sloju nervnih niti, zbog čega i imaju plamenast izgled, dok dublja imaju više ovalan oblik. Ostala masivnija krvarenja su posljedica teških arteriosklerotskih promjena na žilama i mogu biti smješteni pre, intra ili subretinalno. Masivnija retinalna krvarenja nismo registrirali osim kod jedne pacijentice.

Edem papile našli smo kod 4 hipertoničara, što je dokaz da je bolest došla u najtežu fazu i neliječeni unutar jedne godine, prema većini autora, umiru od renalne insuficijencije ili vaskularnih komplikacija. Nakon intenzivne internističke terapije, kod sva 4 pacijenta u roku od 6 mjeseci edem pupile je potpuno nestao i oni se održavaju na životu kroničnom dijalizom.

Gartner sa saradnicima je 1975. godine u opsežnoj eksperimentalnoj studiji hipertenzivne retinopatije na majmunima dokazao gotovo sve promjene kao i kod čovjeka, osim pojave mikroaneurizmi i izlaska fluoresceina oko cotton-wool žarišta, što je 1962. Dollery prvi prikazao. Opisane promjene kod hipertenzivne retinopatije koje su učestalije što je 
dijastolički tlak viši nije problem diferencirati i klasificirati. Međutim, promjene na žilama koje ovom prethode su znatno teže.

Da li je oftalmolog u mogućnosti da na osnovu promjena na žilama predvidi nastup retinopatije i upozori internistu? Mikuni je sa saradnicima 1961. godine, mjereći kalibar i tlak u krvnim žilama retine kod 73 zdrave osobe i 80 hipertončara, našao da postoji signifikantna razlika u kalibru žila i odnosu arterija - vena između II i III stupnja, kao i odnosu arterijalnog retinalnog tlaka i općeg tlaka kod II i III stupnja te zaključuje da kao praktični znak akcelerantne maligne hipertenzije treba smatrati pad omjera kalibra arterija - vena ispod $70 \%$ i porast omjera tlaka iznad $70 \%$.

Očito da oftalmolog na osnovu promjena u kalibru žila retine može dati značajne podatke internisti, mada je teško tačno predvidjeti nastup retinopatije. Promjene na fundusu treba cijeniti u sklopu sa ostalim nalazima, dobi bolesnika i duljinom trajanja hipertenzije.

Posebno je teško diferencirati početne promjene na žilama od normalnog nalaza. Tako Kogan i saradnici (cit. Svardsudd) iznose da u tumačenju nalaza na fundusu na bazi dva stupnja - normalan ili ne - postoje među iskusnim ispitivačima razlike od $20-42 \%$, a kod istog ispitivača od $10-$ $33 \%$ i pored upotrebe fundus fotografije.

Kod mladih osoba sa elastičnim krvnim žilama, ako hipertenzija traje kraće vrijeme, ne moraju se naći nikakve promjene, što smo i mi utvrdili kod naših mlađih hipertoničara, dok u slijedećoj fazi dolazi do opće konkstrikcije retinalnih arterija izraženije na terminalnim granama. Arteriole postaju blijede, izravnane, granaju se pod oštrim uglom, fenomeni križanja nisu jako naglašeni, mada vene mogu biti distalno kongestionirane. Drukčiji je nalaz na krvnim žilama ako hipertenzija nastupa kasnije, kad već postoji involutivna skleroza i arterioskleroza. Tada već prisutne organske promjene ili ubrzane hipertenzijom u zidu žile mijenjaju njen lumen, izgleda refleksa (bakreni, srebreni) sa naglašenim fenomenima križanja. Veće arteriole su obično vijugave, a manje terminalne, ravne i uske. Postoje i lokalna suženja uz vijugavost venula u makularnoj regiji. Tako nastaje kombinirana slika koju je u 
umjerenim slučajevima hipertenzije teško razlikovati koliko je posljedica, a koliko uzrok hipertenzije. Zbog toga i klasifikacija hipertenzivnih promjena na fundusu, po Keith, Wageneru i Barkeru, kod umjerene hipertenzije u dobi iza 40, 45 godina kod I i II stupnja ne daje strogo specifičnu diferencijaciju promjena u procjeni težine hipertenzije. Kirkendall nalazi zamjerke ovoj podjeli zbog miješanja hipertenzivnih i arteriosklerotskih promjena, kao i davanju iste težine tvrdim i mekim eksudatima te strijarnim i okruglim hemoragijama.

6.

Modificirana klasifikacija retinalnih promjena po Scheiu (1953.) diferencira arteriosklerotske od hipertenzivnih promjena, što je vrlo instruktivno, a u praksi ne uvijek lahko djeljivo, pogotovo kad se radi o starijim hipertoničarima. Postoje i druge podjele $\mathrm{u}$ želji da se te promjene što bolje diferenciraju, ali su u osnovi sve iste.

Interesantno je mišljenje grupe švedskih autora na čelu sa Svardsuddom koji smatraju da ne trebaju nikakve podjele, već da se svi pojedinačni simptomi na fundusu kod hipertenzije označe sa plus ili minus. Ovo objašnjavaju time da je i onako vrlo mali broj III i IV stupnja i da su svi ostali I i II stupnja, te ovako klasificirani unose više nejasnoće nego jasnoće. Očito da nije problem u klasifikacijama, već u sposobnosti uočavanja i tumačenja nalaza na fundusu, u čemu bi trebalo sve više koristiti fundus fotografiju kao objektivni pokazatelj postojećeg stanja i radi komparacije pri kontrolnim pregledima. Odnos funduskopskog nalaza i snimke fundusa mogli bi uporediti sa dijaskopskim nalazom i RTG snimkom.

\section{ZAKLJUČAK}

$\mathrm{Na}$ osnovu naših rezultata možemo zaključiti da je nalaz na fundusu u procjeni težine arterijske hipertenzije, kao i praćenja uspjeha terapije uz mjerenje tlaka, jedan od najvažnijih nalaza. Težina promjena na fundusu raste sa porastom dijastoličkog tlaka. Dok je u grupi hipertoničara sa dijastoličkim tlakom do $110 \mathrm{~mm} \mathrm{Hg}$ normalan nalaz bio u $44 \%$, a promjene na fundusu samo I i II stupnja, u grupi sa dijastoličkim tlakom 
iznad $130 \mathrm{~mm} \mathrm{Hg}$, normalan nalaz je bio samo u $4 \%$, a hipertenzivne promjene III i IV stupnja u $18 \%$.

Uz visinu dijastoličkog tlaka, značajnu ulogu ima duljina trajanja hipertenzije i dob bolesnika. U dobi do 30 godina normalan nalaz na fundusu nađen je u $83 \%$.

Utvrdili smo signifikantno značajnu razliku u težini promjena na fundusu, ukoliko je dijastolički tlak bio veći od $130 \mathrm{~mm} \mathrm{Hg} \mathrm{u} \mathrm{odnosu} \mathrm{na}$ promjene koje smo našli na fundusu ako je dijastolički tlak bio manji od $110 \mathrm{~mm} \mathrm{Hg}$.

\section{LITERATURA}

1. Alajbegović R.; Milanović Lj.; Bijedić M.; Očne bolesti. Sarajevo. Svjetlost 1982.

2. Budimlić E.; Oftalmologija. Bihać. Grafičar. 2008.

3. Bušić M.; Seminaria Ophthalmologica. Osijek. Cerovski d. o. o. 2012.

4. Cerovski B.; Oftalmologija. Zagreb. 2012.

5. Čupak i sar.; Oftalmologija. Nakladni zavod. Globus. Zagreb 1995.

6. Đaković S.; Reooftalmografska i oftalmopletizmografska studija intraokularne cirkulacije krvi,produkcije i drenaže sobne vodice

7. Vojniković B.; Primarni glaukom. Pula 1984., 343 - 75

8. Kanski J.; Clinical Ophthalmology, 1994.

9. Kendić S.; et all. Gerijatrijska njega. Bihać. Grafis. 2010.

10. Kozomara R.; Klinička oftalmologija. Glas srpski. Banja Luka 2000.

11. Kozomara R.; Priručnik iz oftalmologije za porodičnog ljekara. Naučna knjiga. Banja Luka 1998.

12. Sefić M.; Budimlić E.; Oftalmologija.Grafičar. Bihać 2002.

13. Sefić M.; Oftalmologija za studente medicine i stomatologije. TKP Šahinpašić. Sarajevo 2000.

14. Šikić J.; Oftalmologija. Zagreb. Kratis. 2003. 
Budimlic Enver, $\mathrm{PhD}$

\section{THE IMPORTANCE OF FUNDUS IDENTIFICATION IN THE EVALUATION OF ARTERIAL HYPERTENSION}

\section{Summary}

This paper deals with the results of findings on the fundus at 226 patients with hypertension in relation to the height of diastolic pressure and the age of a patient and the changes on the fundus during therapy.

The finding on the fundus is one of the most important findings in the evaluation of difficulty of Arterial hypertension. With the increase of diastolic pressure, the severity of changes on the fundus also grows. Beside diastolic pressure, duration of hypertension and age of patient play an important role.

Keywords: arterial hypertension, diastolic blood pressure, hypertonicholdings. 


\section{الدكتور أنور بوديمليتش}

أهمية نتائج فحص أسفل العين في تقدير ارتفاع ضغط الدم الشرياني

\section{الخلاصة}

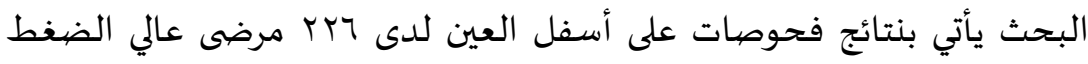

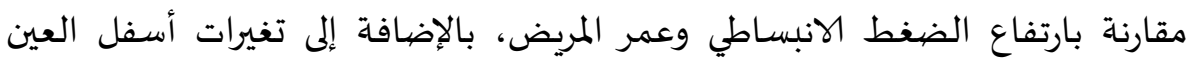
خلال عملية المعالجة.

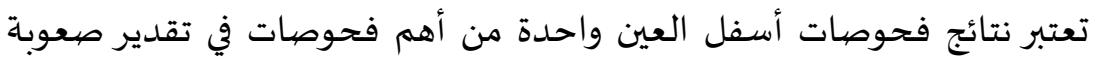

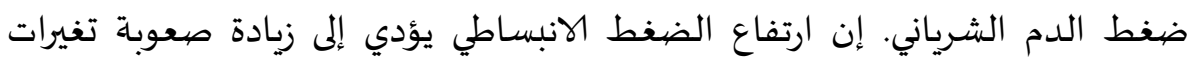

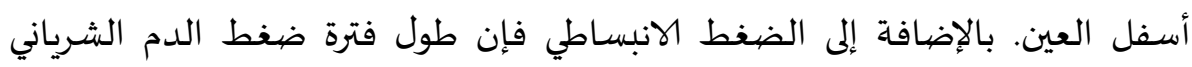
وعمر المريض لهما أهمية كبيرة. الكلمات الرئيسة: ضغط الهمية كيرة. الدم الشرياني، الضغط الانبساطي، مرض أسفل العين نتيجة الضغط. 